\title{
Comparing community birdwatching and professional bird monitoring with implications for avian diversity research: a case study of Suzhou, China
}

Yan Zhou ${ }^{1,2^{*}} \mathbb{D}$, Anping Chen ${ }^{3 *}$, Jenny Q. Ouyang ${ }^{4}$, Yanlin Liu ${ }^{5}$, Aiyu Zheng ${ }^{6}$, Zaixi Yang ${ }^{1}$, Yong Zhang ${ }^{1}$, Bin Wang ${ }^{7}$, Yifei Jia ${ }^{2}$, Shengwu Jiao ${ }^{2,8}$, Qing Zeng ${ }^{2}$ and Changhu Lu ${ }^{1}$

\begin{abstract}
Background: In the past decades, birdwatching as a hobby developed rapidly and produced ample scientific records that have aided conservation efforts. Therefore, it is increasingly attractive to promote avian research by providing data from birdwatching.

Methods: We compared records from 16 years of community birdwatching and a 1 -year formalized bird monitoring in Suzhou, China to study the similarities and differences between the two monitoring methods.

Results: We showed that within the 325 bird species recorded by the two methods, an annual average of 108 species were documented by community science and 223 bird species were recorded by 1-year formalized monitoring. Measured by the number of bird species recorded per survey trip, the bird monitoring activity of community birdwatchers was significantly lower. Furthermore, the monitoring intensity of community birdwatching measured as the average survey trips per site each survey year was also lower than that of formalized bird monitoring. In addition, community birdwatchers preferred urban landscapes to rural areas.
\end{abstract}

Conclusions: Community birdwatching could record the majority of local birds and complements the professional surveys in avian research. Well designed and coordinated community science can be used to expand the knowledge about avian distribution and population dynamics. These findings are critical for the development of conservation science with regard to community involvement.

Keywords: Avian diversity, Birdwatching, Community science, Conservation, Formalized bird monitoring

\section{Background}

The term of citizen science refers to scientific investigations and research activities involving non-professionals (Bonney et al. 2014; Kullenberg and Kasperowski 2016),

\footnotetext{
*Correspondence: zhouyan.eco@foxmail.com; apchen1111@gmail.com

${ }^{1}$ Co-Innovation Center for Sustainable Forestry in Southern China/

College of Biology and the Environment, Nanjing Forestry University, Nanjing 210037, China

${ }^{3}$ Department of Biology, Colorado State University, Fort Collins, CO 80523, USA

Full list of author information is available at the end of the article
}

which was gradually instead of the term of community science for the exclusive connotations surrounding the word citizen (Audubon website 2018). In the past few decades, community science has grown rapidly in ecology and conservation (McKinley et al. 2017). Community science, especially the development in species monitoring, has accumulated a large number of observation records, providing first-hand data for scientific research (Gardiner et al. 2012; Kosmala et al. 2016). Compared to traditional research run by professional researchers, an apparent advantage of community science is its potential

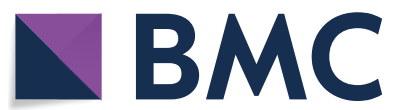

(c) The Author(s) 2020. This article is licensed under a Creative Commons Attribution 4.0 International License, which permits use, sharing, adaptation, distribution and reproduction in any medium or format, as long as you give appropriate credit to the original author(s) and the source, provide a link to the Creative Commons licence, and indicate if changes were made. The images or other third party material in this article are included in the article's Creative Commons licence, unless indicated otherwise in a credit line to the material. If material is not included in the article's Creative Commons licence and your intended use is not permitted by statutory regulation or exceeds the permitted use, you will need to obtain permission directly from the copyright holder. To view a copy of this licence, visit http://creativeco mmons.org/licenses/by/4.0/. The Creative Commons Public Domain Dedication waiver (http://creativecommons.org/publicdomain/ zero/1.0/) applies to the data made available in this article, unless otherwise stated in a credit line to the data. 
to engage many more participants for long-term research on a wider spatial scale, e.g., in conservation biology and agricultural science research (McKinley et al. 2017; Abbott et al. 2018). Coupled with the rapid development of information technology, such as social networking and messaging platforms, volunteers from different countries and different fields can effectively carry out simultaneous scientific research and monitoring, further highlighting the value of community science (McKinley et al. 2017). However, data quality and distribution from community science can vary due to differing skill levels and frequency of participation so researchers should exercise caution when employing these datasets (Theobald et al. 2015). To use data generated by community science, it is essential to first assess its data quality and usefulness, ideally with the data obtained by professional researchers (Gilfedder et al. 2019).

Birds are among the most effective indicator organisms of environmental change because of their rapid response to habitat change (Stephens et al. 2016). Many birds are brightly colored, vocally pleasant, and highly distinguishable between species, making them the most commonly used target organisms for community science activities (Dickinson et al. 2010; Tulloch et al. 2013). As early as the 19th century, the National Audubon Association of the United States carried out systematic birdwatching activities and published a large number of research results based on community birdwatching data. The establishment of the eBird database further enables avian scholars to access and analyze publically available community birdwatching data (Wood et al. 2011; Sullivan et al. 2014). Data from community science can be used to generate long-term trends that could complement data from traditional surveys, and the research on avian species distribution, population dynamics, response to climate change, and the conservation of avian distribution hotspots could also be strengthened using community data (Crick 2010; Hochachka et al. 2012; Walker and Taylor 2017; Hong et al. 2018; Horns et al. 2018).

China is one of the richest countries in avian species diversity (Zheng 2017). However, community bird watchers did not emerge in Chinese mainland until the 1980s (Ma et al. 2013; Walther and White 2018). Since then, a large number of birdwatching enthusiasts have appeared, whose footprints have largely covered all of China (Ma et al. 2013; Walther and White 2018). Enthusiastic community bird watchers often self-upload birdwatching records to the China Bird Recording Center (http:// www.szbird.org.cn/birdtalker.net/index.asp) and the China Bird Watching Center (http://www.birdreport.cn/) (Walther and White 2018). These data have already been used for the study of the distribution and population dynamics of birds (Li et al. 2012; Hu et al. 2017; Zhou et al. 2019a, b). However, due to inherent shortcomings of non-professional birdwatching, such as less-skilled birdwatchers, etc. (Bart 2005), the use of community birdwatching data for addressing important scientific questions, such as avian species distribution and diversity, needs careful attention. Currently, comparative studies to assess the quality and scope of the rapidly growing community birdwatching data in China are still lacking, which prevents researchers from appropriately using these data to investigate avian biogeography, population dynamics, and conservation.

At present, birdwatching is still a "middle-class activity" in China, which is more often conducted in more prosperous regions (Ma et al. 2013; Wang 2015; Walther and White 2018). Hence, we selected Suzhou, one of the most developed prefecture-level cities in China, as the research area. Suzhou is a developed city in China, located close to the hotspot of migratory birds. Many Suzhou volunteers are enthusiastic birdwatchers with somewhat varied birdwatching willing or skill level, better reflecting Chinese community birdwatching. We conducted a year of formalized bird monitoring in Suzhou. We then compared our formalized data with data obtained from community birdwatching. Our goal was to study the similarities and differences between the two bird monitoring methods, such as checklist and monitoring intensity, and to explore the potential use of community birdwatching data for avian diversity research and conservation.

\section{Methods \\ Survey area}

Suzhou City $\left(30^{\circ} 47^{\prime}-32^{\circ} 02^{\prime} \mathrm{N}, 119^{\circ} 55^{\prime}-121^{\circ} 20^{\prime}\right.$, Fig. 1) is located in the southeastern part of Jiangsu Province, east of the Taihu Plain in the Yangtze River Delta, with a total area of $8848 \mathrm{~km}^{2}$. Low-elevation (2-4 m above the sea level) plains account for $54.9 \%$ of the city's total area, followed by water body ( $42.5 \%$ of the total area). The low hills with an altitude of 100-350 m scatter the west of the city and on the Taihu Island. The Yangtze River and the Beijing-Hangzhou Canal run through the northern part of the city, and the number of rivers and streams reaches more than 20,000. Located in the middle of the migratory route for East Asian-Australasian migratory birds, Suzhou's abundant wetlands make the area an important wintering ground and stopover for migratory birds (Qi 2008).

Suzhou has a subtropical monsoon maritime climate with four distinct seasons. The annual average temperature is $15.7^{\circ} \mathrm{C}$ (range: $3.1^{\circ} \mathrm{C}$ in January and $28^{\circ} \mathrm{C}$ in July). The average annual precipitation is about $1100 \mathrm{~mm}$, concentrated in April to September, with the highest rainfall 

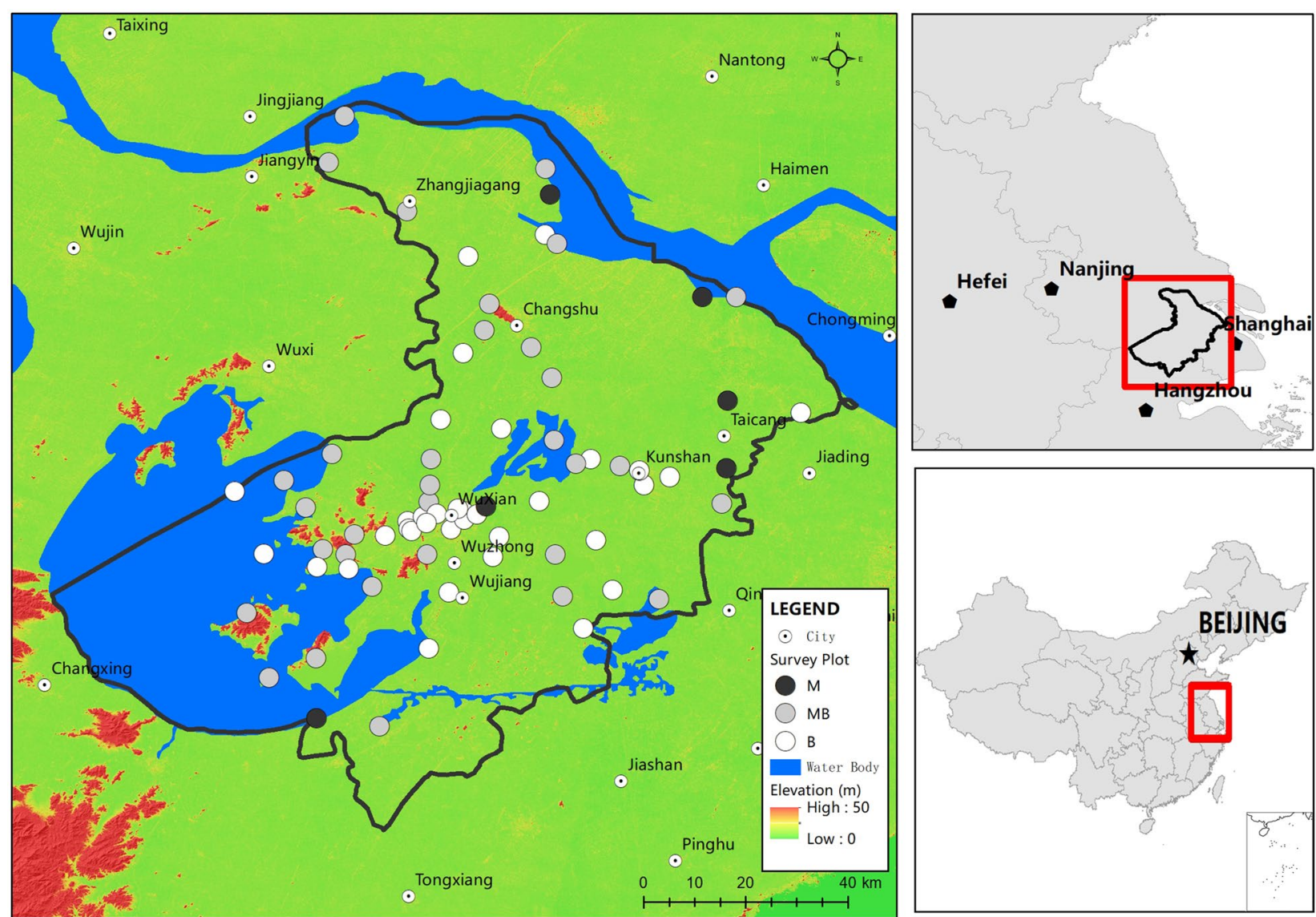

Fig. 1 Distribution of bird monitoring zones in Suzhou. The dark line shows the border line of the Suzhou prefecture city. The grey circles indicate sites where both formalized bird monitoring and community birdwatching occur. The dark circles indicate where formalized bird monitoring occurs, and the white circles indicate where community birdwatching occurs

in June and the lowest in December and January (Qi 2008).

\section{Search and collation of community birdwatching records}

The China Bird Recording Center was launched in 2002 and houses birdwatching records as early as January 1997. The China Bird Watching Center launched in 2014 contains birdwatching records from January 2001 onwards. Both data centers require bird species, number of individuals, location, date, and habitat description for records. We downloaded all bird-watching data records from Suzhou from the two data centers. Some birdwatchers upload the same birdwatching record on both websites, in which case we used one copy from the China Bird Watching Center. We found 471 community birdwatching events which had occurred at 66 sites (Fig. 1) from July 2003 to June 2018. Bird species nomenclature in this study follows Zheng (2017).

\section{Formalized bird survey}

From July 2017 to June 2018, we conducted the first comprehensive expert survey of bird species and distribution in Suzhou. In doing so, we divided the Suzhou area into $3505 \mathrm{~km} \times 5 \mathrm{~km}$ grids. We chose 38 grids out of the total of 350 grids for the survey, i.e., a sampling intensity of more than $10 \%$. The grid selection was based on pre-survey field scout and local knowledge provided by the local forestry administration to ensure most bird hotspots were covered. The survey covers all bird habitat types in Suzhou, including river wetlands, lake wetlands, hilly woodlands, farmland and urban landscapes (Fig. 1). The 1-year survey also considered the seasonal differences in the avian community in Suzhou and included one full bird migration season. For each surveyed grid, a $2 \mathrm{~km}$-long route was set and the frequency of field investigations was once a month, accumulating to 456 surveys in total. For each field investigation, the team consisted of 2-3 experienced investigators (at least 5 years of experience). The team was equipped with one single-lens 
telescope and one drone, in addition to one pair of binoculars, one camera and one hand-hold GPS for each investigator. One investigator observed and counted birds, and the other recorded them. The field investigation occurred at 6:00-9:00 in the morning or 15:00-18:00 in the evening, along pre-scheduled routes at a walking speed of $1-2 \mathrm{~km} / \mathrm{h}$. We only recorded species name and abundances when we visually confirmed the species with binoculars and monoculars. To avoid repeated recording, we counted only the birds flying from the front to the back of the observers, but not those flying from back to the front. For the birds that could not be identified on the spot, we used a camera to take pictures to help with identification. In some open waters not conducive to investigation, we used drones to take photos and videos for auxiliary investigations.

\section{Data analysis}

All statistical analyses were conducted with the SPSS program version 18.0. We used non-parametric tests as the distributions of observed species number for community birdwatching failed to pass the normal distribution test. The list length is how many species were recorded in a single trip, which is important information for qualifying the absence of a particular species from a list, reflecting the bird species monitoring effort when all bird checklist are collected from a certain region (Szabo et al. 2010). Consequently, we used the list length as an indicator of the professionalism of community investigators. We used the Mann-Whitney test to assess the difference in the number of bird species per survey trip between professional bird survey and community birdwatching. In order to better compare the list length from two methods of bird monitoring, we randomly sampled from the professional survey data collected intensively within 1 year (original sample size $=456$ ) to simulate data collected from monthly professional monitoring within 1 year, 5 years, 10 years and 15 years. New sample size was thus $12,60,120,180$, respectively. We performed 1000 replicates for all the 4 scenarios to show the percentage of $1000 p$ values that are significant $(p<0.05)$ between professional bird survey and community birdwatching. Based on the ratio of the number of surveys to the number of areas surveyed each year, we measured the intensity of annual birdwatching and formalized bird monitoring.

\section{Results}

During 2002-2018, the retrieved community birdwatching events documented a total of 305 species in Suzhou. On an average year from July to June, there were about 108.1 (range: 26-242) species documented by community birdwatching. Compared to the 161 species recorded in 2017-2018 by community birdwatching, the 1-year professional survey recorded 223 bird species (Fig. 2). Overall, by combining professional survey and community birdwatching records, 325 bird species were recorded in Suzhou.

Some 203 bird species were recorded by both professional survey and community birdwatching. For the 102 species of birds recorded by community birdwatchers

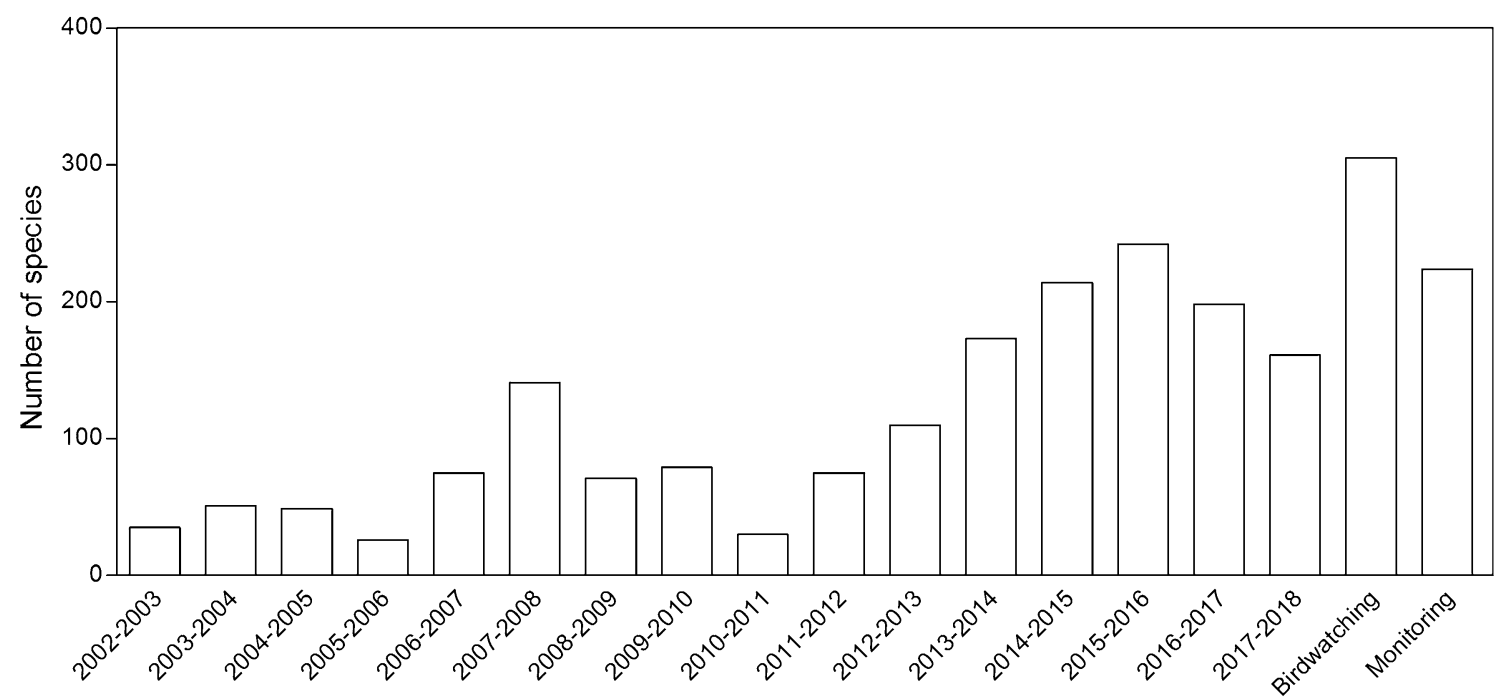

Fig. 2 The number of species recorded by formalized bird monitoring and birdwatching. The total number of species recorded by community birdwatching varied each year from 2002 to 2018. The total species richness recorded by birdwatchers from 2002-2018 was 305, and the total species richness recorded by formal bird monitoring in 2017-2018 was 223 
but not in the professional survey, nearly half ( 49 species) of them were migrants, followed by wintering migratory birds ( 29 species). On the other hand, among 20 species that were observed in the professional survey but not by community birdwatchers, 11 species were resident birds and 7 species were migrants (Fig. 3).

The average number of bird species surveyed per single trip was smaller for community birdwatching than formal bird monitoring $(20.24 \pm 14.14$ species by community birdwatchers, $21.30 \pm 7.76$ by professionals, $p<0.01$; Mann-Whitney test). The random sampling also shows that formal bird monitoring has a longer list length than community birdwatching (Fig. 4). The distribution of list length for a single survey showed a normal distribution pattern for formalized bird monitoring, while the list length of a single trip by community birdwatchers enormously varies and shows a "tailed distribution" (Fig. 5). The annual average list length of community birdwatching varies in different monitoring years, ranging between 6.55 (2008-2009) and 28.91 (2015-2016) (Fig. 6). For years with community birdwatching survey numbers greater than 50 (2007-2008, 2013-2014, 2014-2015, and 2015-2016), a Mann-Whitney test shows that only 2015-2016 had a significant difference in average list length between birdwatching and monitoring $(p<0.01)$.

Both formalized bird monitoring and community birdwatching focused more on lake habitats (Table 1), and both methods differed little in monitoring intensities for river and woodland landscape. Compared with formalized bird monitoring, community birdwatching was more likely to be carried out in urban landscapes and not conducted in the farmland area (Table 1).

Over the 1-year formalized bird monitoring period, there were 456 survey trips for the professionally

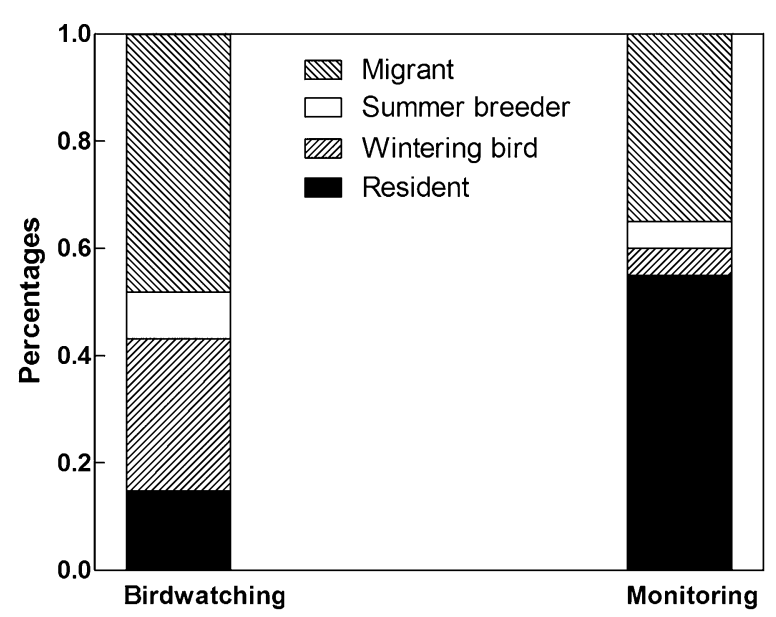

Fig. 3 The ratios of different residential types of the avian species only recorded in birdwatching and formalized bird monitoring investigated 38 survey sites, indicating once a month per site (Fig. 7). In comparison, there were a total of 471 survey trips for all community birdwatching trips combined over a span of 16 years at 66 survey sites (Fig. 7). Furthermore, the monitoring intensity ranged between 1 and 3.3 by community birdwatching from 2002-2003 to $2017-2018$, in comparison to 12 by the professional survey.

Compared with the consistent monitoring intensity of the professional survey, the monitoring intensity of community birdwatching fluctuates monthly (Fig. 8).

\section{Discussion}

Community science in bird surveys, such as the eBird database for the United States, has allowed scientists to answer questions in avian population ecology and conservation biology, but birdwatching has only been active for the past two decades in China. As a result, the databases for bird counts have not been checked and validated with scientific monitoring. We attempted to address this lack by comparing data from community science birdwatching and professional monitoring. We found that although the number of bird species recorded by birdwatching per year increased over the past two decades, community bird monitoring is influenced by personal activity of birdwatching, monitoring site selection, and lack of consistence, which may result in biased results for formal inquiries.

Over the past 16 years, community birdwatchers have recorded a total of 305 species of birds, including several rare species that are occasionally seen in Suzhou, such as the Scaly-sided Merganser (Mergus squamatus) and the Black-faced Spoonbill (Platalea minor). Moreover, many years of continuous community engagement in birdwatching can cover a broader area than professional surveys that are often limited by people and funding. The intensity of professional surveys sometimes is lower than that of community birdwatching at some hotspots of birdwatching. This broad spatial and temporal coverage allows community birdwatchers to record occasionally migratory bird species that are less likely to be encountered by formalized bird monitoring in a short period. Records of community birdwatching also revealed at least four species of birds that have never been recorded in the Jiangsu Province before, including Rufous-faced Warbler (Abroscopus albogularis), Common Ringed Plover (Charadrius hiaticula), and Verditer Flycatcher (Eumyias thalassinus) (Yang et al. 2018; Huang et al. 2019; Zhou et al. 2019a, b). Overall, our results suggest that community birdwatching well complements the expensive professional surveys in investigating and monitoring bird resources and their spatio-temporal dynamics especially 
a

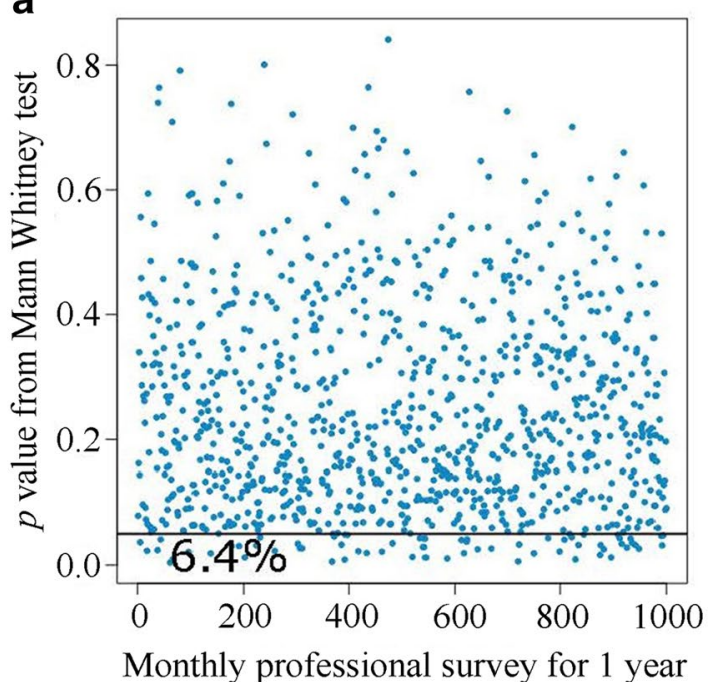

C

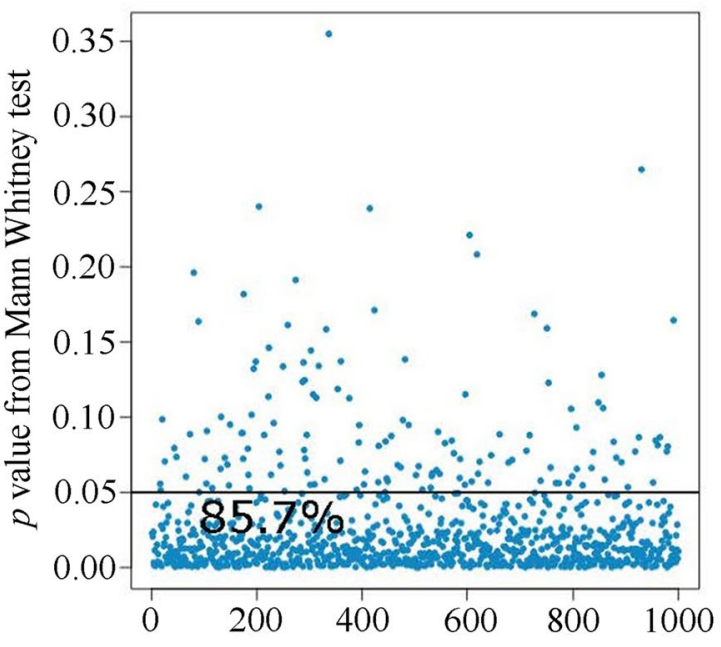

Monthly professional survey for 10 years b

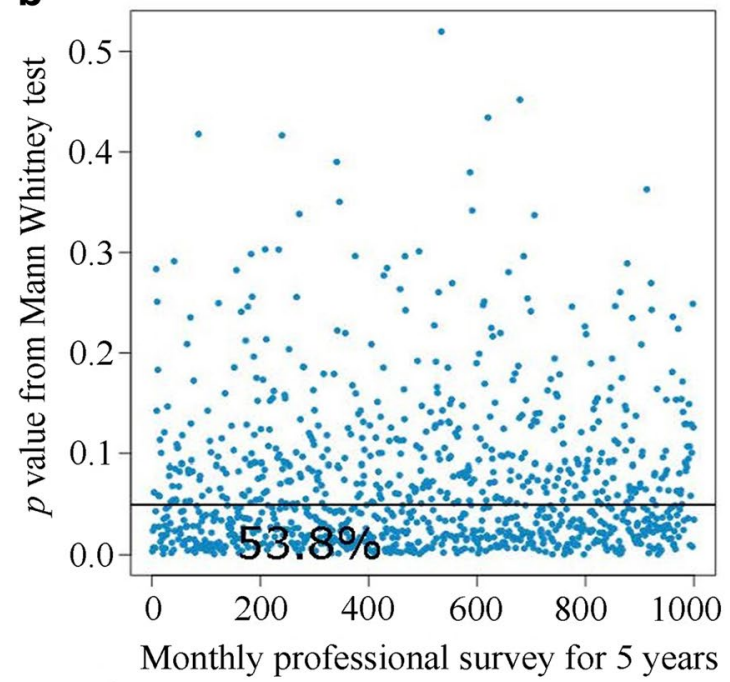

d

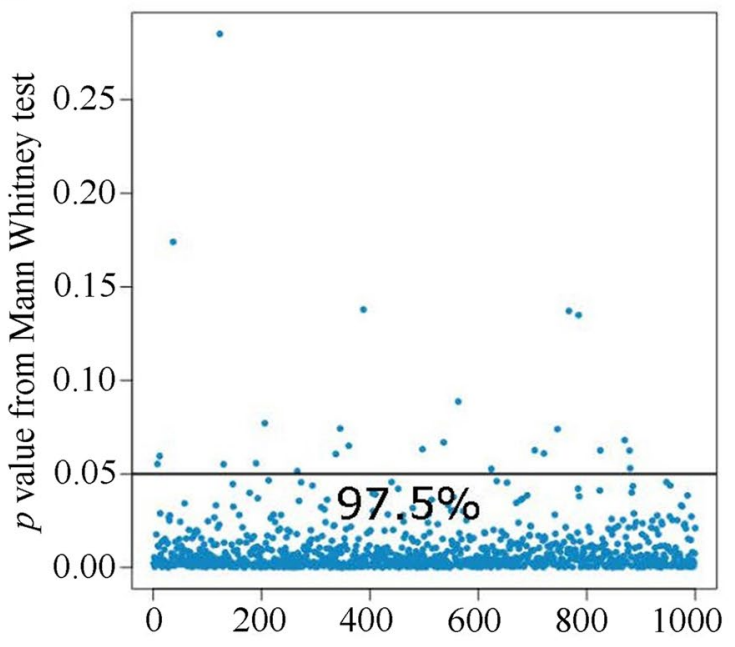

Monthly professional survey for 15 years

Fig. 4 The $p$ values from Mann-Whitney tests with the alternative hypothesis of professional survey generate longer species lists than the community science. Each blue point represents a $p$ value attained from the Mann-Whitney test after resampling, and we performed 1000 replicates for 1 year $(\mathbf{a}), 5$ years $(\mathbf{b}), 10$ years $(\mathbf{c})$, and 15 years $(\mathbf{d})$. The percentage level shows the percentage of $1000 p$ values that are significant $(p<0.05)$

when professional survey cannot be run (Chase and Levine 2016; Horns et al. 2018).

However, we need to bear in mind that compared to professional surveys, records of community birdwatching suffer from several intrinsic limitations and thus should be treated with caution. Finding more species and new distribution of bird species is a strong motivation behind many community birdwatchers (Scott et al. 1999). When selecting the survey area, community birdwatchers prefer wetland and woodland landscapes where more bird species are often found, but pay little attention to farmland landscapes that are mostly associated with common species, such as sparrows and magpies (Table 1). In addition, community birdwatching is rarely systematically designed in the survey time and routes, making it difficult to represent the overall occurrence of bird species in a region. This lack of systematic and harmonized design also makes it hard to conduct inter-region and inter-survey comparisons (Greenwood 2007).

Community birdwatchers tend to choose the period over a year when birds are abundant, which often means 


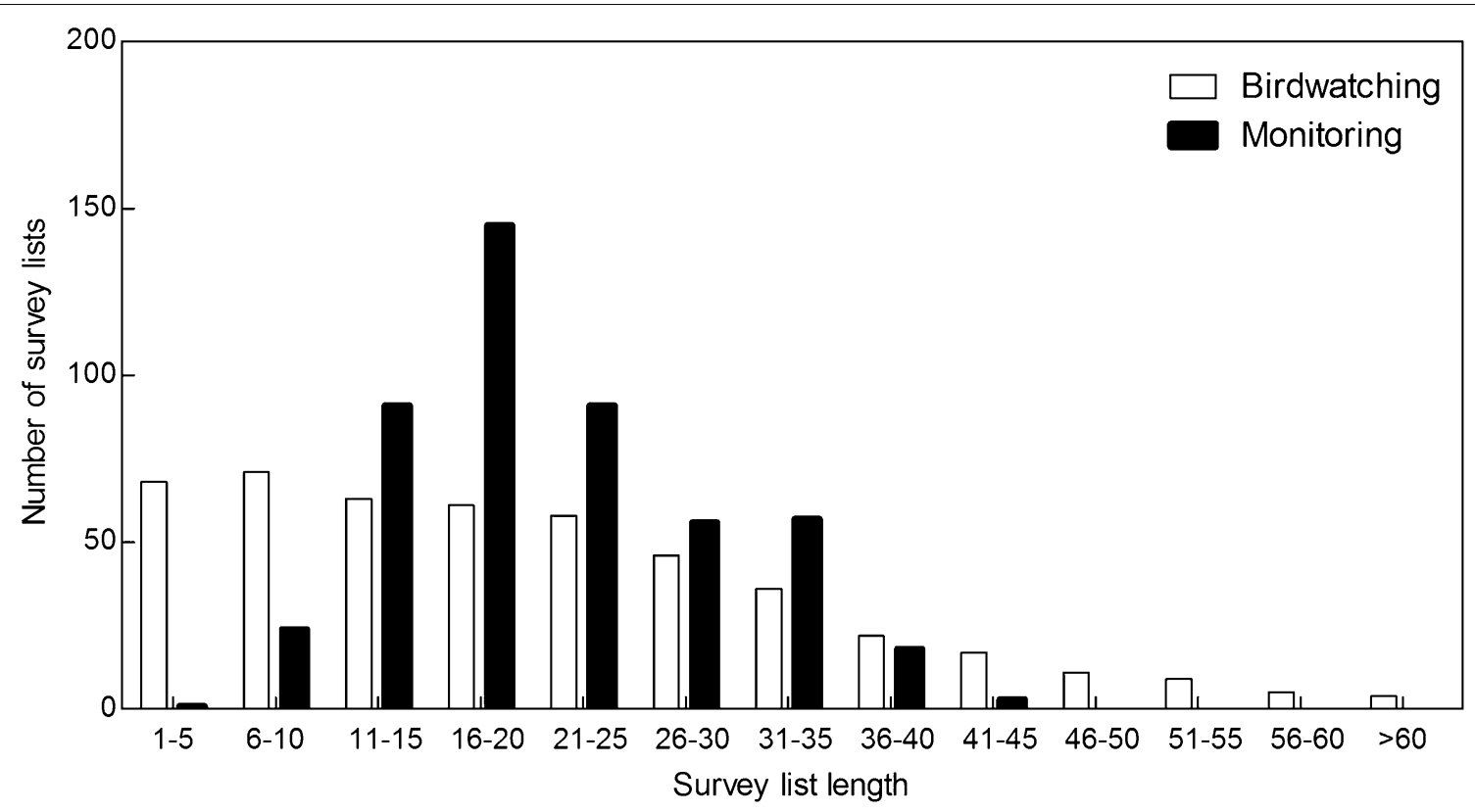

Fig. 5 The distribution of survey list length for formalized bird monitoring and birdwatching

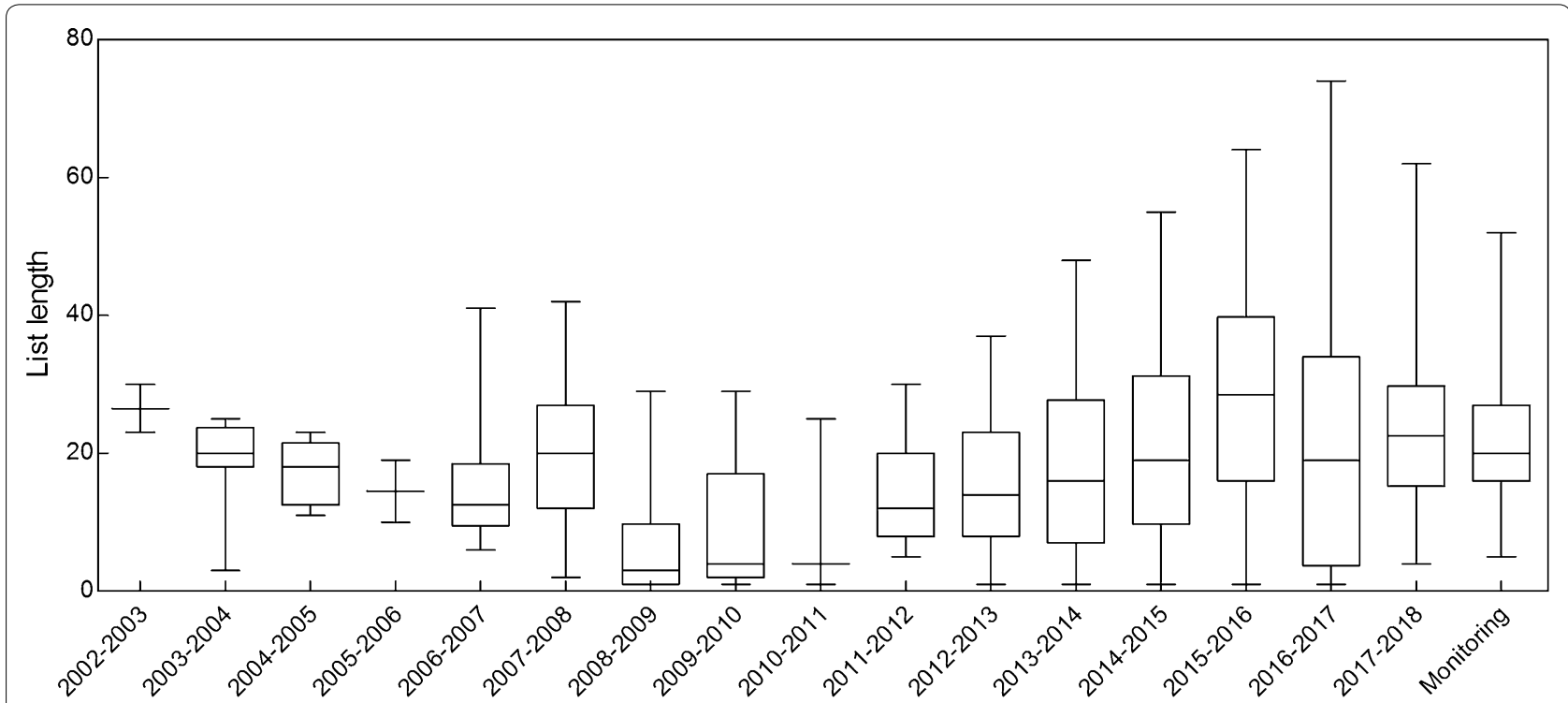

Fig. 6 The average list length of formalized bird monitoring and birdwatching. The box plot reflects maximum value, minimum value, 1 st quartile, 3rd quartile and median value

Table 1 Landscape types covered by formalized bird monitoring and birdwatching

\begin{tabular}{lllllll}
\hline & Lake & River & Woodland & Urban area & Farm & Total \\
\hline Monitoring & $23(60.5 \%)$ & $3(7.9 \%)$ & $8(21.1 \%)$ & $1(2.6 \%)$ & $3(7.9 \%)$ & 38 \\
Birdwatching & $35(53.0 \%)$ & $6(9.1 \%)$ & $11(16.7 \%)$ & $14(21.2 \%)$ & $0(0 \%)$ & 66 \\
\hline
\end{tabular}




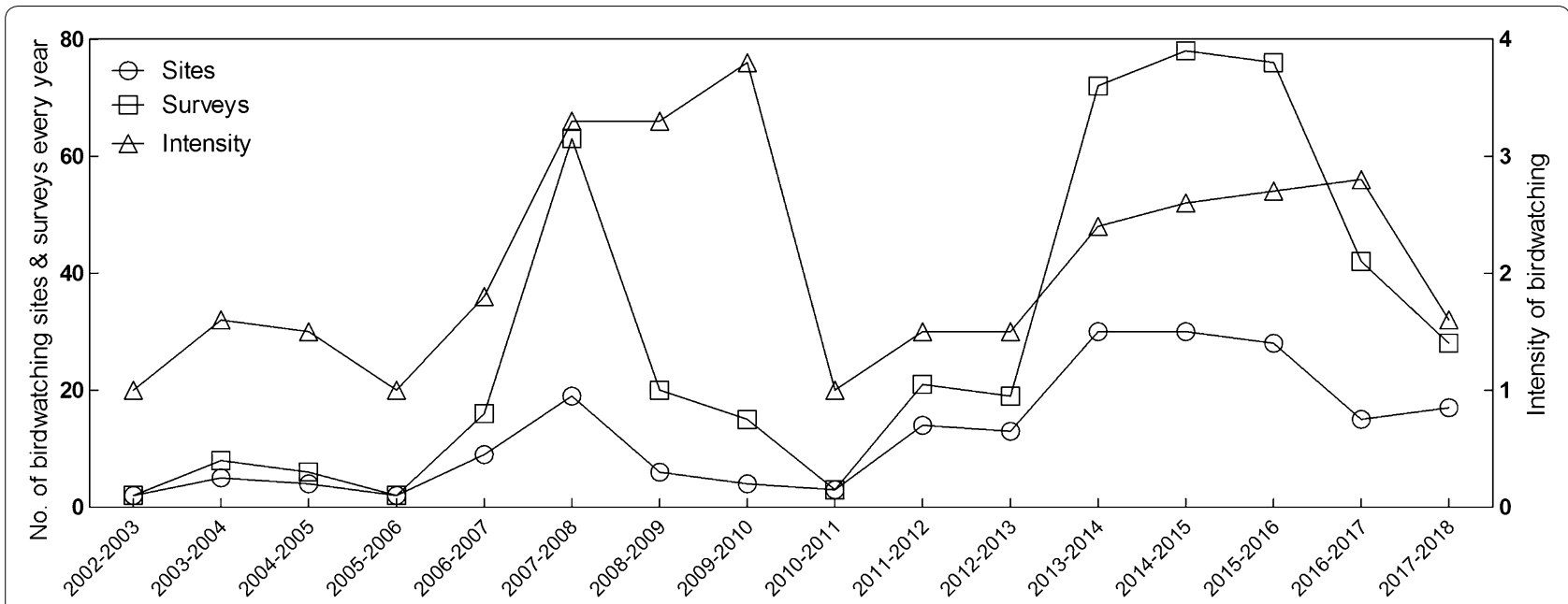

Fig. 7 The number of survey sites, surveys and monitoring intensities per year of birdwatching along 2002-2018

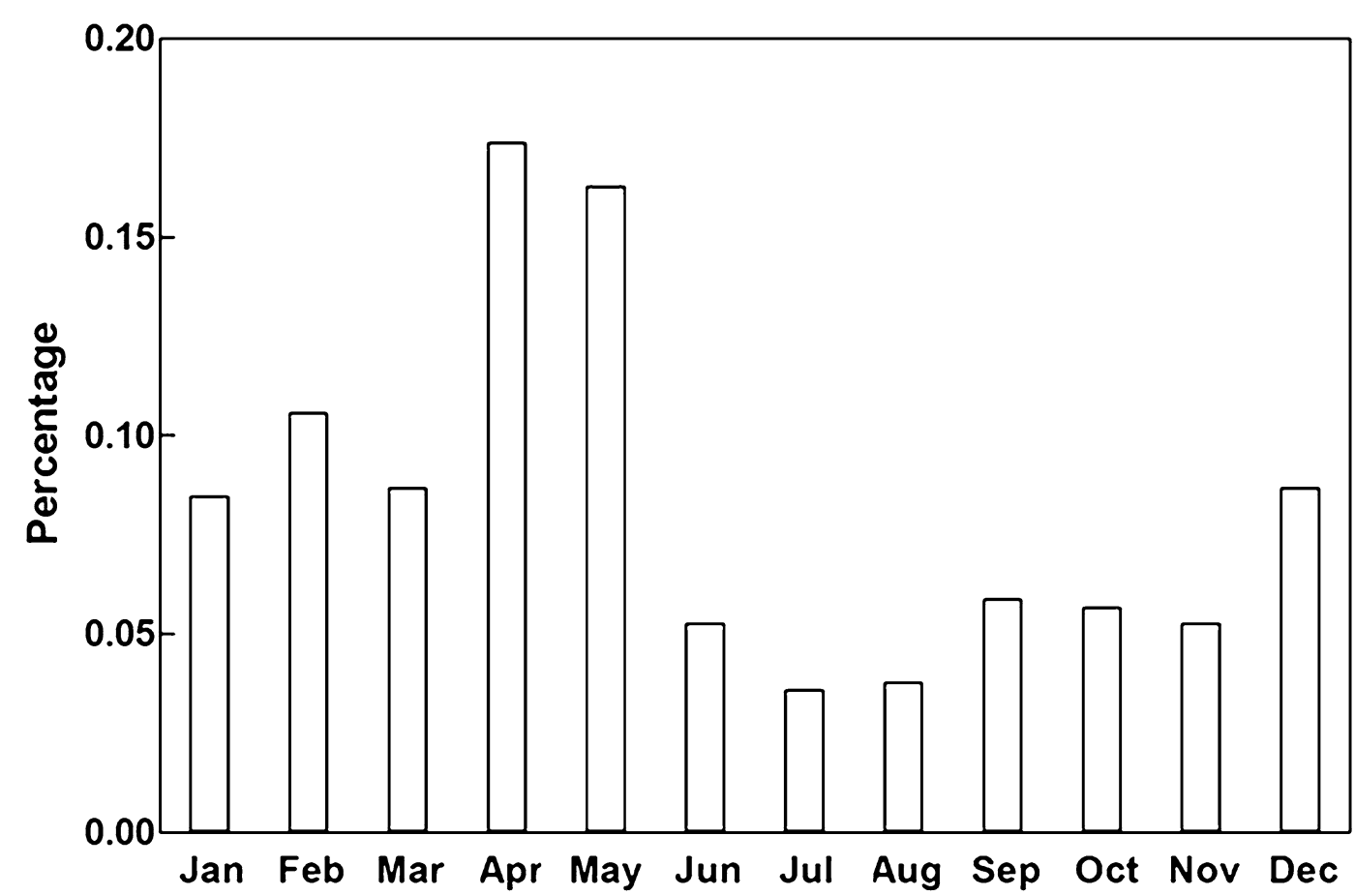

Fig. 8 The monthly distribution of birdwatching activity from 2002 to 2018

migratory seasons. As the spring migration period is often short in Suzhou, the appearance of a large abundance of various migratory birds in this short period leads to particularly higher number of birdwatching activities in the spring migration period than in other seasons. Especially in summer, birdwatching activities fall sharply (Fig. 8). The lack of continuity of community birdwatching activities and the different frequency of birdwatching between months make it difficult to maintain sufficient monitoring intensity, and may miss species that do not appear often in peak migratory seasons. For example, although community birdwatching shows records for 16 years in Suzhou, there are still 11 resident bird species that have never been recorded, including the Grey-capped Pygmy Woodpecker (Dendrocopos canicapillus) and Grey-headed Parrotbill (Paradoxornis gularis). 
The remaining 9 resident birds not recorded by community birdwatching are Collared Crow (Corvus torquatus), Barred Owlet (Glaucidium cuculoides), Greater Barbet (Megalaima virens), Oriental Scops Owl (Otus sunia), Plumbeous Water-redstart (Rhyacornis fuliginosus), Striated Prinia (Prinia criniger), Lesser Necklaced Laughingthrus (Garrulax monileger), Blue Whistling-thrush (Myophonus caeruleus) and Grey-headed Woodpecker (Picus canus). Therefore, the current intensity and seasonal coverage of community birdwatching in Suzhou is not sufficient to reflect the seasonal dynamics of bird species in different types of landscapes. In addition, the activity of community birdwatchers is highly uneven, reflected in the fact that the species list length of singletrip records varies greatly $(\mathrm{SD}=14.14$, Fig. 6$)$ and most of the list length of community birdwatching are less than that of formalized bird survey (Figs. 4 and 5), indicating that the birdwatching activities of many community scientists need to be strengthened or well-designed and birdwatching plan should be employed when watching birds. Besides personal activity of birdwatching, the difference between males and females, adults and juveniles, and the difference of birdwatching distance could impact the checklist of both community birdwatching and formalized bird survey, which was not taken into account in this study. Control experiments need to be run in future studies to clearly demonstrate the accurate differences between the two methods.

The extensive engagement of community birdwatching has become a highly useful tool in supplement to formalized bird monitoring, although the results of this study indicate that there are still various deficiencies in the current community birdwatching. Moreover, with careful planning and training, community birdwatchers can be organized to work along with professional ornithological researchers and become a part of formalized bird monitoring (Bai et al. 2015; Zeng et al. 2018). For example, well-designed community birdwatching plans such as the Christmas Bird Count $(\mathrm{CBC})$ by eBird and the North American Breeding Bird Survey (NA-BBS) led by the USGS Patuxent Wildlife Research Center and many other organizations have provided researchers with a large amount of reliable monitoring data (Sauer and Link 2011; Amano et al. 2018). In China, universities, research institutions, and professional organizations have also started to provide ornithological training courses and organize students and amateurs to carry out bird monitoring (Ma et al. 2013). Examples include the Survey of the Yellow Sea Waterbirds by the Wetland International China Office in collaboration with multiple universities (Chen et al. 2019) and the China Coastal Waterbirds Synchronization Survey organized by China Coastal Waterbird Census Group (Bai et al. 2015). The integration of community birdwatching with professional efforts has greatly expanded the monitoring network for China's bird species, and found dozens of bird species that have never been recorded in China (Liu et al. 2013).

Nevertheless, there is still a long way to go before largescale applications of community birdwatching records (Ma et al. 2013). At present, the main problems faced by Chinese bird watchers include the lack of bird watching organizations, the shortage of funds, and the lack of communication between birdwatchers. In order to cope with these problems, some environmental protection foundations in China, such as the SEE Foundation, have begun to systematically cultivate birdwatching organizations through financial and intellectual support. Some environmental agencies such as the Shan Shui Conservation Center and the China Birdwatching Association have launched national-scale species monitoring programs such as China Nature Watch, National Wintering Survey of Scaly-sided Merganser, which organizes birdwatchers for endangered birds monitoring (Zeng et al. 2018). The development of birdwatching in China is also in sync with the rapid development of network technology. China's earliest birdwatching website and eBird were launched in 2002, and many birdwatchers learned to publicly share their data. However, not all birdwatchers observe and record important population and habitat information, such as the number of individual species, behavioral and habitat data, other than just recording the species name. This lack of inconsistence of important information could prevent researchers from conducting in-depth analyses of community birdwatching data. In the future, with the development of China's economy, we can expect to see more and more birdwatchers (Sekercioglu 2002). More resources need to be invested to maximize the scientific literacy of the birdwatchers, and to satisfy their curiosity about nature and bird species. We also need to enable close communications between birdwatchers and professional researchers, so that more bird research can benefit from the development of birdwatching with the help of big data technology.

\section{Conclusions}

Our study suggests that the current intensity of community birdwatching could record the majority of local birds and complements the expensive professional surveys in investigating and monitoring avian resources and species spatio-temporal dynamics. Meanwhile, the imbalance of personal activity of birdwatching and spatio-temporal distribution of community birdwatching limits the extensive utilization of community birdwatching in avian research. Increasing investment in community birdwatching and improving 
the scientific literacy of birdwatchers will contribute to avian research in the coming years.

\section{Acknowledgements}

We thank Yan Zhang, Fang Zhang, Xiaoran Zhang, Pan Chen, Guohai Wang, Taiyu Chen, Caihong Lu, Peng Xu and Manyu Zhang for their help in field work. We thank the staff of Suzhou Forestry Station for their support in field work.

\section{Authors' contributions}

Data curation: Y. Zhou, AC, JQO, YL, AZ, ZY, Y. Zhang. Formal analysis: Y. Zhou, $A C$, JQO, YL, AZ, ZY, Y. Zhang. Funding acquisition: Y. Zhou, CL. Investigation: Y. Zhou, ZY, Y. Zhang, BW, YJ, SJ, QZ, CL. Methodology: Y. Zhou, AC, JQO. Project administration: Y. Zhou. Writing of the original draft and revision:Y. Zhou, AC, $\mathrm{JQO}, \mathrm{YL}, \mathrm{AZ}$. All authors read and approved the final manuscript.

\section{Funding}

This research was supported by Social Development Research Program of Jiangsu Province Science and Technology department (No. BE2019773) and Priority Academic Program Development of Jiangsu Higher Education Institutions (PAPD).

\section{Availability of data and materials}

The datasets used and/or analyzed during the current study are available from the corresponding author on reasonable request.

\section{Ethics approval and consent to participate}

Not applicable.

\section{Consent for publication}

Not applicable.

\section{Competing interests}

The authors declare that they have no competing interests.

\begin{abstract}
Author details
${ }^{1}$ Co-Innovation Center for Sustainable Forestry in Southern China/College of Biology and the Environment, Nanjing Forestry University, Nanjing 210037, China. ${ }^{2}$ School of Nature Conservation, Beijing Forestry University, Beijing 100083, China. ${ }^{3}$ Department of Biology, Colorado State University, Fort Collins, CO 80523, USA. ${ }^{4}$ Department of Biology, University of Nevada, Reno, NV 89557, USA. ${ }^{5}$ Institute of Forest Ecology Environment and Protection, Chinese Academy of Forestry, Beijing 100091, China. ${ }^{6}$ Department of Ecology and Evolutionary Biology, Princeton University, Princeton, NJ 08544, USA. ${ }^{7}$ College of Lifesciences, Hunan Normal University, Changsha 410006, China. ${ }^{8}$ Research Institute of Subtropical Forestry, Chinese Academy of Forestry, Fuyang 311400, China.
\end{abstract}

Received: 3 March 2020 Accepted: 19 June 2020

Published online: 23 June 2020

\section{References}

Abbott BW, Moatar F, Gauthier O, Fovet O, Antoine V, Ragueneau O. Trends and seasonality of river nutrients in agricultural catchments: 18 years of weekly citizen science in France. Sci Total Environ. 2018;624:845-58.

Amano T, Szekely T, Sandel B, Nagy S, Mundkur T, Langendoen T, et al. Successful conservation of global waterbird populations depends on effective governance. Nature. 2018;553:199-202.

Audubon.org. Why we're changing from "Citizen Science" to "Community Science". 2018-05-02. https://debspark.audubon.org/news/why-were-chang ing-citizen-science-community-science.

Bai Q, Chen J, Chen Z, Dong G, Dong J, Dong W, et al. Identification of coastal wetlands of international importance for waterbirds: a review of China Coastal Waterbird Surveys 2005-2013. Avian Res. 2015;6:35-50.

Bart J. Monitoring the abundance of bird populations. Auk. 2005;122:15-25.

Bonney R, Shirk JL, Phillips TB, Wiggins A, Ballard HL, Miller-Rushing AJ, et al. Next steps for citizen science. Science. 2014;343:1436-7.
Chase SK, Levine A. A framework for evaluating and designing citizen science programs for natural resources monitoring. Conserv Biol. 2016;30:456-66.

Chen K, Lv Y, Wang L, Chen Q, Lv X, Jiang M, et al. Diversity and distribution of waterbirds during spring in wetlands around Huanghai Sea and Bohai Sea in China. Wetl Sci. 2019;17:137-45.

Crick HQP. The impact of climate change on birds. Ibis. 2010;146:48-56.

Dickinson JL, Zuckerberg B, Bonter DN. Citizen science as an ecological research tool: challenges and benefits. Annu Rev Ecol Evol S. 2010;41:149-72.

Gardiner MM, Allee LL, Brown PM, Losey JE, Roy HE, Smyth RR. Lessons from lady beetles: accuracy of monitoring data from US and UK citizenscience programs. Front Ecol Environ. 2012;10:471-6.

Gilfedder M, Robinson CJ, Watson JEM, Campbell TG, Sullivan BL, Possingham HP. Brokering trust in citizen science. Soc Nat Resour. 2019;32:292-302.

Greenwood JJD. Citizens, science and bird conservation. J Ornithol. 2007;148:S77-124.

Hochachka WM, Fink D, Hutchinson RA, Sheldon D, Wong W-K, Kelling S. Dataintensive science applied to broad-scale citizen science. Trends Ecol Evol. 2012;27:130-7.

Hong S-Y, Lin H-S, Walther BA, Shie J-E, Sun Y-HI. Recent avain poisonings suggest a secondary poisoning crisis of black kites during the 1980s in Taiwan. J Raptor Res. 2018;2018(52):326-37.

Horns JJ, Adler FR, Sekercioglu CH. Using opportunistic citizen science data to estimate avian population trends. Biol Conserv. 2018;221:151-9.

Hu RC, Wen C, Gu YY, Wang H, Gu L, Shi XY, et al. A bird's view of new conservation hotspots in China. Biol Conserv. 2017;211:47-55.

Huang Y, Peng S, Zhou Y, Su T, Lu C. A new record of verditer flycatcher (Eumyias thalassinus) in Jiangsu Province. Sichuan J Zool. 2019;38:379.

Kosmala M, Wiggins A, Swanson A, Simmons B. Assessing data quality in citizen science. Front Ecol Environ. 2016;14:551-60.

Kullenberg C, Kasperowski D. What is citizen science? A scientometric MetaAnalysis. PLOS ONE. 2016;11:16.

Li X, Liang L, Gong P, Liu Y, Liang F. Bird watching in China reveals bird distribution changes. Chin Sci Bull. 2012;57:2956-63.

Liu Y, Wei Q, Dong L, Lei J. On an update of recent new bird records in China. Chin J Zool. 2013;48:750-8.

Ma ZJ, Cheng YX, Wang JY, Fu XH. The rapid development of birdwatching in mainland China: a new force for bird study and conservation. Bird Conserv Int. 2013;23:259-69.

McKinley DC, Miller-Rushing AJ, Ballard HL, Bonney R, Brown H, Cook-Patton $\mathrm{SC}$, et al. Citizen science can improve conservation science, natural resource management, and environmental protection. Biol Conserv. 2017;208:15-28.

Qi R. Study on habitat fragmentation and its impacts on biodiversity at urban areas: a case of Suzhou. PhD Thesis. Shanghai: East China Normal University. 2008.

Sauer JR, Link WA. Analysis of the north american breeding bird survey using hierarchical models. Auk. 2011;128:87-98.

Scott D, Baker SM, Kim C. Motivations and commitments among participants in the great Texas birding classic. Hum Dimens Wildl. 1999;4:50-67.

Sekercioglu CH. Impacts of birdwatching on human and avian communities. Environ Conserv. 2002;29:282-9.

Stephens PA, Mason LR, Green RE, Gregory RD, Sauer JR, Alison J, et al. Consistent response of bird populations to climate change on two continents. Science. 2016;352:84-7.

Sullivan BL, Aycrigg JL, Barry JH, Bonney RE, Bruns N, Cooper CB, et al. The eBird enterprise: an integrated approach to development and application of citizen science. Biol Conserv. 2014;169:31-40.

Szabo JK, Vesk PA, Baxter PWJ, Possingham HP. Regional avian species declines estimated from volunteer-collected long-term data using List Length Analysis. Ecol Appl. 2010;20:2157-69.

Theobald EJ, Ettinger AK, Burgess HK, DeBey LB, Schmidt NR, Froehlich HE, et al. Global change and local solutions: tapping the unrealized potential of citizen science for biodiversity research. Biol Conserv. 2015;181:236-44.

Tulloch AIT, Possingham HP, Joseph LN, Szabo J, Martin TG. Realising the full potential of citizen science monitoring programs. Biol Conserv. 2013;165:128-38

Walker J, Taylor PD. Using eBird data to model population change of migratory bird species. Avian Conserv Ecol. 2017;12:4. 
Walther BA, White A. The emergence of birdwatching in China: history, demographics, activities, motivations, and environmental concerns of Chinese birdwatchers. Bird Conserv Int. 2018;28:337-49.

Wang M. Systematic survey and volunteer birding of waterbirds in China, history and present analysis and comparison. Master Thesis. Hefei: University of Science and Technology of China. 2015.

Wood C, Sullivan B, lliff M, Fink D, Kelling S. eBird: engaging birders in science and conservation. PLoS Biol. 2011;9:e1001220.

Yang Z, Su T, Lu C, Zhou Y. A new record of common ringed plover (Charadrius hiaticula) in Jiangsu Province. Sichuan J Zool. 2018;37:562.

Zeng Q, Wei Q, Lei G. Contribution of citizen science towards cryptic species census: "many eyes" define wintering range of the Scaly-sided Merganser in mainland China. Avian Res. 2018;9:6
Zheng G. A checklist on the classification and distribution of the birds of China (Third edition). Beijing: Science Press; 2017.

Zhou Y, Wei M, Lu C. Rufous-faced warbler (Abroscopus albogularis) found in Southern Jiangsu. Chin J Zool. 2019a;54:14.

Zhou Y, Jing L, Jia Y, Lei G, Yao Y, Lu C, et al. Population dynamics of four endangered cranes and landscape patterns of habitats in the East Dongting Lake during recent 30 years. J Lake Sci. 2019b;31:1415-23.
Ready to submit your research? Choose BMC and benefit from:

- fast, convenient online submission

- thorough peer review by experienced researchers in your field

- rapid publication on acceptance

- support for research data, including large and complex data types

- gold Open Access which fosters wider collaboration and increased citations

- maximum visibility for your research: over 100M website views per year

At BMC, research is always in progress.

Learn more biomedcentral.com/submissions 